\title{
Two cheers for Migration Studies
}

\author{
Steven Vertovec
}

\author{
Correspondence: vertovec@mmg. \\ mpg.de \\ Max Planck Institute for the Study \\ of Religious and Ethnic Diversity, \\ Göttingen, Germany
}

\begin{abstract}
Over the last 30 years, as the CrossMigration project demonstrates, Migration Studies has been positively institutionalized in a number of ways. Further, a number of new theoretical interventions have significantly altered the ways we understand migration. What unfortunately has not changed, I believe, is the low level of impact that academic studies of migration has had on public understanding. For these reasons, we can call for a limited "two cheers for Migration studies", but not the conventional three cheers.

Keywords: Migration Studies, institutionalization, transformations, transnationalism, complexity, communication
\end{abstract}

Migration Studies is a multi- and inter-disciplinary research field that, over the past 30 years, has substantially both changed and remained the same. As part of the EUHorizon 2020 CrossMigration project, Asya Pisarevskaya, Nathan Levy, Peter Scholten and Joost Jansen have evidenced how this process - particularly the change side - has developed (Levy et al. 2020; Pisarevskaya et al. 2019). On the one hand, it is not remarkable that there has been a large increase in the number of journals and articles in the field of Migration Studies over 30 years, since this is the case with practically all sciences. General academic output has globally doubled every 9 years (Van Noorden 2014). On the other hand, however, what is remarkable - as these authors show through innovative analyses of Migration Studies literature - is the concurrence of several important trends that have taken place during this period of expansion. Also, over these decades, a number of new theoretical interventions have significantly altered the ways we understand migration. In these ways, Migration Studies has changed, in very positive ways moreover. What unfortunately has not changed, I believe, is the low level of impact that academic studies of migration has had on public understanding. For these reasons, we can call for a limited "two cheers for Migration Studies", but not the conventional three cheers.

\section{First cheer: institutionalization}

The CrossMigration articles indicate, among other things, a broad pattern of institutionalization characterizing the field. This includes findings that: the field has undergone a slow process of internationalization; it has witnessed considerable

(c) The Author(s). 2020 Open Access This article is licensed under a Creative Commons Attribution 4.0 International License, which permits use, sharing, adaptation, distribution and reproduction in any medium or format, as long as you give appropriate credit to the original author(s) and the source, provide a link to the Creative Commons licence, and indicate if changes were made. The images or other third party material in this article are included in the article's Creative Commons licence, unless indicated otherwise in a credit line to the material. If material is not included in the article's Creative Commons licence and your intended use is not permitted by statutory regulation or exceeds the permitted use, you will need to obtain permission directly from the copyright holder. To view a copy of this licence, visit http://creativecommons.org/licenses/by/4.0/. 
disciplinary and methodological variation; across a growing body of literature, there has been an increasing diversification of topics generally, greater connection between some topics, and an inconsistent fragmentation - or decreasing connectedness -- of others. Despite a proliferation of topics, approaches and methods, the authors demonstrate a 'coming of age' of the research field. This has come about through the emergence of a common, globalized academic field of scholars across numerous disciplines working on the same, similar or related topics and often referring to each other. We should also consider, as key evidence of institutionalization, the substantial growth in the number of migration-related courses and degrees at universities worldwide. These are all developments that are undoubtable, noteworthy and welcome. One cheer for Migration Studies.

However, for me, several questions immediately arise from this coming of age thesis. First, to what extent are scholars included in this trend (a) actually aware of their common framing as 'Migration Studies scholars', and (b) are they comfortable with that? Here I'm thinking of colleagues in certain disciplines in certain countries who - for personal reasons stemming from national academic cultures and professional pressures - only want to be thought of as a specialist within their discrete disciplines. For them, multi- and inter-disciplinarily may well be disdained. I've certainly met German economists and American sociologists, to name but two examples, who may well have been included in the overview analysis of the field because they work on data concerning refugees or post-migrant ethnic minorities, but who would probably reject the designation of their work as 'Migration Studies'.

Second, as many scholars have debated for years, it is contestable what counts as Migration Studies. The boundaries of this field are terribly vague and porous. What topics belong in, which should be out (or at least entered with qualifiers)? As someone who has done work with national ethnic minorities in different contexts, years or generations after an earlier period of migration, I have always felt uncomfortable when this field-of-its-own gets subsumed under Migration Studies. While the term 'migration-related diversity' is often used, I think that should be reserved for the diversities that relate directly to actual migrants themselves ... not diversity that exists in a society because of a long past migration. It is a tricky matter, to be sure. In the CrossMigration study, it is noted that 'black studies' has been a prominent topic in Migration Studies over three recent periods. With much of this topic comprised of studies regarding Black Americans (whose history based on slavery is only marginally comparable to most contemporary international migration), its fit in Migration Studies is highly questionable. Arguably for some, too, the inclusion of all studies of racial and ethnic minorities within Migration Studies might inherently equate or 'migrantize' such purported minorities as being akin to foreign 'others' (Anderson 2019). Relatedly, the study of racism is clearly relevant to migrants, albeit not focused on migrants. Is it inside or outside of Migration Studies? A far different topic, citizenship, represents a parallel, burgeoning and important field of literature with obvious relevance to migration. However, only some publications concern migrants. Is the topic in or out?

These doubts notwithstanding, the proliferation of themes and subjects within Migration Studies is certainly something to be celebrated. For us scholars, an ever-richer array of studies has broadened our horizons, brought new issues to our attention, and helped serve to link a number of topics. 


\section{Second cheer: transformations}

The CrossMigration study points to a number of developments within Migration Studies over 30 years, grouped together as a process of institutionalization. Another important series of developments that have affected the field are ones that cannot be measured by bibliographic analyses alone. These concern some of the ways that concepts and approaches have impacted on the way social scientists have come to research and understand migration patterns and processes - indeed that have shaped many basic ways we think about migration. While the field is grounded in a number of 'classics' (Cohen 2019), over the past 30 years a set of newer publications and approaches have had significant impacts. These call for a second cheer for Migration Studies. Examples of such transformative concepts include the so-called new economics of migration, methodological nationalism and transnationalism. Each of these broke a kind of mould in the way migration was conventionally approached and understood within social science.

Classical migration theory had long rested on a view that migration is driven by individual migrants making rational choices to move to places with higher wages. By the early 1990s, with an approach deemed the new economics of migration, this shifted to an understanding that migration decisions are made by entire households and family networks as part of strategies to collectively minimize risk and produce benefits for all (e.g., Stark and Bloom 1985; Massey et al. 1993). Also, the shifted perspective recognized that deprivation is relative and that low to middle income people tend to be the ones who migrate, rather than the poorest.

Another transformative notion in Migration Studies has been methodological nationalism, particularly in its formulation by Wimmer and Glick Schiller (2002). It describes and criticizes the ways in which the concept of the nation-state, as a kind of containers of peoples, laws and heritage, came to be regarded as a natural and inherent form of organization. Indeed, such an interpretation was eventually taken for granted as a fundamental social and political formation, including among social scientists. The task becomes that of breaking free from methodological nationalism in order to gain a fully theoretical perspective on social networks, trends, processes and influences that crosscut or spill over from nation-states societies. The notion has gained great salience. One problem with its success, however, is that reference to Wimmer and Glick Schiller's piece has become rather de rigueur within Migration Studies, including in many studies that are actually and solely about discrete nation-state societies. That is, it has become easy to cite the piece without taking on board its message.

Wimmer and Glick Schiller's article was directly linked with the concept of transnationalism. Commencing in the early 1990s, transnationalism is a concept that disrupted several accepted views of migration. Foremost was the view of migration in which it was assumed that migrants left their places of origin once and for all to settle and assimilate in new contexts. Consequently, the world was largely divided into sending- and receiving-countries. Instead, transnationalism underscores the fact that migrants tend to maintain extensive familial, social, economic and political links with their places of origin, creating and maintaining ways of life and social fields that combine origin and destination points (see, among others, Glick Schiller et al. 1992; Portes et al. 1999; Vertovec 1999; Levitt 2001). This 'realization' also led to considerable attention to the ways that transnational communities impact on homeland 
development, especially through remittances. The figure below, based on an examination of 2026 publications, reflects the cross-disciplinary interest in transnationalism that began in the 1990s and has steadily boomed until the present (showing the number of times the term appeared in titles, keywords and abstracts - with special thanks to Margherita Cusmano and Heike Sieber at the Max Planck Institute).

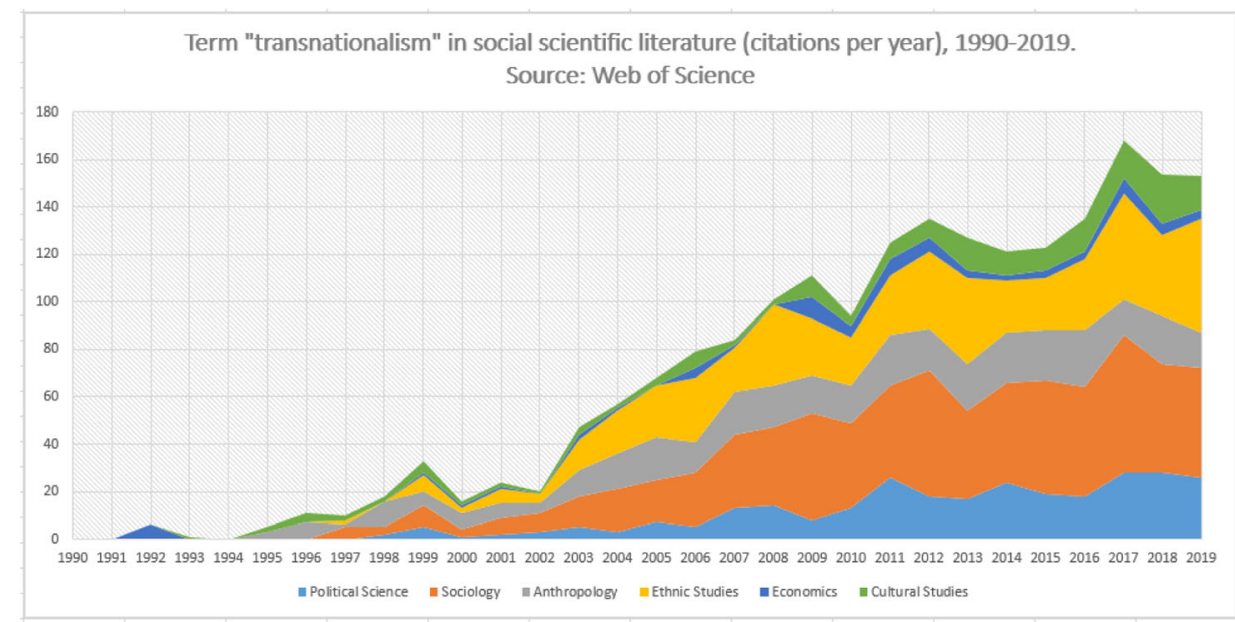

It was no coincidence that the rise of notions of methodological nationalism and transnationalism (accompanied by a boom in studies of diasporas) occurred at the same time as a proliferation of interest and publications on globalization. The 1990s and especially the early 2000s were a time of expanding global linkages of many kinds - and of academic interest in them.

At present - dare I say - in some quarters, the concept of super-diversity (Vertovec 2007, 2019; Meissner and Vertovec 2015) represents a kind of transformative concept and approach to researching and understanding complexity in migration flows and outcomes. This comes at a time when, arguably, many aspects of national and world society are becoming more complex. Precisely for this reason, Migration Studies needs to gear itself for a different kind of engagement.

\section{No cheer (yet): complexity and communication}

The impact of Migration Studies works on policy, at any scale, has been sporadic and uneven. Further, its impact on public understanding and opinion has been unremarkable at best to imperceptible at worst. For this reason, in my view, Migration Studies still does not merit a full three cheers because of its failures in public communication.

This is not for want of trying. Numerous academics have spent countless hours researching and writing for policymakers and trying to work with and through journalists. There are, to be sure, examples out there where academic Migration Studies have made a difference. Yet on the whole, policymakers either ignore what does not suit their agenda or notoriously cherry-pick findings and recommendations. Journalists often do much the same, drawing on academics only to tell the stories they themselves want (or think the public wants) to hear and tell.

Practically every week, some issue concerning migration appears in the headlines. Borders said to need tightening, flows deemed out of control, more migrants dead in the Mediterranean, integration processes purportedly failed. What is the most effective role 
for scholars in Migration Studies within a public sphere apparently gripped by such issues?

One conventional role for scholars has long been that of feeding the public sphere with professional views and factual data. Particularly now, with the salience of migration matters particularly high (see, for instance, Dennison and Geddes 2019), there are a great many academic researchers who wish to work closely with civil society organizations, concerned citizens and policymakers to bring about a better public understanding of migration and its outcomes. This was witnessed not long ago in an open letter calling for a paradigm change in public debates around migration. Led by Virginie Guiraudon and Thomas Piketty and signed by more than 700 academics, the call was simultaneously published on 28 June 2018 in Le Monde, La Repubblica and The Guardian.

Another role for scholars has been to provide correctives. In this role, academics intervene in the public sphere to rectify some reported data, interpretation or political statement that they consider false or, more often, overly simplistic. This has often been the case concerning matters such as one-dimensional understandings of immigrant integration, stereotypic images of immigrant ghettos and parallel societies, and ideas of national identity. A perpetual danger with the scientist's corrective role is that of appearing as a patronizing elite, talking down to members of the public who they consider ignorant.

Much to the irritation of journalists and policymakers, social scientists routinely answer almost any query with the standard response, 'it's complicated'. By that, we usually mean that most social processes and outcomes are multi-causal and involve the interplay of several factors if not several processes in interaction. When asked to streamline or make more digestible their views and findings, some academics are taken aback or even refuse, horrified at the ostensible prospect of dumbing-down their work. But what should we do with our approaches to, and conclusions concerning, what are indeed complex conditions, interplays and processes? Instead of recoiling, social scientists should welcome opportunities to engage policymakers or parts of the media in order to encourage and inspire the treatment of major topics like migration in more multifaceted ways in an attempt to help foster modes of complex thinking.

Not least with regard to migration and diversity issues, members of the public rightfully want to know why something has happened in the way it has. Doing their job to meet such interests, journalists and policymakers look for reasons and causes - but sometimes only basic or singular ones. This often goes hand-in-hand with the use of highly limited, common sense categories like economic vs forced migration or zerosum views of the labour market.

Given that social scientists regularly research and write about multiple causes and interdependent processes, we should not just resist what we might see as simplification, but convince others of the merit of asking, in all instances, 'what other factor(s) or process (es) might be influencing this phenomenon?' This is akin to what feminist lawyer Mari Matsuda (1991) calls 'the other question': for example, she proposes, when one sees a phenomenon that looks racist, one should also ask: does gender or class have some role in this too? Similarly, 'the other question' is possible with a wide range of matters concerning migration, integration and diversity. 
In this way, more complex questions concerning migration processes should probe the usually multiple, compound drivers behind migration. Rather than a view merely positing that persecution leads to 'refugees' and poverty leads to 'economic migration', the media should be prompted to look for the inherently multifaceted reasons people leave their homelands today. Migration always has multiple causes that influence, trigger and condition one another, and recognizing this is another major contribution of Migration Studies (see especially Black et al. 2011). These are usually factors that are at once political (a state failing to protect and provide for its population, perhaps supporting corruption and a context of violence), social and familial (including aspirations for education, healthcare and life chances), economic (entailing inequalities, food insecurity, collapse economic sectors), environmental (stemming from climate change and environmental degradation), and demographic (especially population growth, but also imbalances in terms of age and the labour market).

More complex questions concerning integration processes require an intersectional approach. This entails recognizing the way that a number of individual characteristics - ethnicity, gender, legal status, language competency, age, neighborhood, and so on - combine to provide opportunities and constraints for an individual within society. This is one of the key spheres in which Matsuda's 'other question' has bearing. Specific combinations or correlations of characteristics are reflected in the pace, direction, processes and indicators of integration (which rightly remains a highly debated concept in Migration Studies).

If significant sectors of the media develop better practices for probing complex questions about migration, it will mark an important step towards stimulating the public themselves to ask more comprehensive questions. Migration Studies scholars can help by offering empirically based, complex narratives. In this way, the general public can be treated as self-equipped with the tools to make their own, more wide-ranging assessments. With perhaps a little nudging, everyone should be able to recognize, seek out and themselves reason-through multi-factor information and interwoven processes. After all, multiple factors and interwoven processes aren't the stuff of advanced Sociology: as described in Jason Mittel's (2015) book, Complex TV, every contemporary mini-series like 'Game of Thrones' or 'Babylon Berlin' is inherently based on these. If people can follow an intricate, multi-threaded mini-series, they should be able to draw connections between a range of migration-related facts and processes, too.

Society itself is becoming ever-more complex, and we should all be better equipped to comprehend it. The task for Migration Studies is not solely to provide journalists, policymakers and the wider public with factual answers to basic questions, but to encourage them to ask more extensive ones. Subsequently, with a degree of more complete information and understanding, public debates into the costs and benefits of migration might then be conducted more productively with advocates using far-ranging evidence, instead of combatively between entrenched camps spouting one-sided arguments. This entails cultivating more complex thinking about migration.

Migration Studies has come a long way in 30 years, as the CrossMigration studies clearly and helpfully show us. This includes not only a proliferation of literature, topics and networks, but also important new ways of describing and thinking about migration. We certainly need to continue to research, publish and think in more innovative and forward-thinking ways about migration. Yet, with such an accumulated depth and breadth 
of analysis and understanding of migration drivers, processes, dynamics and outcomes, we also need to get much better at conveying complex migration dynamics and shaping the ways that migration is discussed and comprehended in the public sphere. This should lead toward more far-reaching policy interventions, with complex solutions addressing complex problems (Scholten In press). Then, hopefully in much less than another 30 years, we will be able to call properly for "three cheers for Migration Studies!"

\section{Author's contributions}

The author(s) read and approved the final manuscript.

Competing interests

The author declares that he has no competing interests.

Received: 1 May 2020 Accepted: 1 May 2020

Published online: 02 October 2020

\section{References}

Anderson, B. (2019). New directions in migration studies: towards methodological de-nationalism. Comparative Migration Studies, 7 https://doi.org/10.1186/s40878-019-0140-8.

Black, R., Adger, W. N., Arnell, N. W., Dercon, S., Geddes, A., \& Thomas, D. S. G. (2011). The effect of environmental change on human migration. Global Environmental Change, 21S, S-S11.

Cohen, R. (2019). Classics in migration - introduction. Migration Studies, 7(2), 266-268,

Dennison, J., \& Geddes, A. (2019). A rising tide? The salience of immigration and the rise of anti-immigration political parties in Western Europe. The Political Quarterly, 90(1), 107-116.

Glick Schiller, N., Basch, L., \& Blanc-Szanton, C. (1992). Towards a transnational perspective on migration: Race, class, ethnicity and nationalism reconsidered. New York: New York Academy of Sciences.

Levitt, P. (2001). Transnational migration: taking stock and future directions. Global Networks, 1(3), 195-216.

Levy, N., Pisarevskaya, A., \& Scholten, P. (2020). Between fragmentation and institutionalization: The rise of migration studies as a research field. Comparative Migration Studies, 8 https://doi.org/10.1186/s40878-020-00180-7.

Massey, D. S., Arango, J., Hugo, G., Kouaouci, A., Pellegrino, A., \& Taylor, J. E. (1993). Theories of international migration: a review and appraisal. Population and Development Review, 19(3), 431-466.

Matsuda, M. (1991). Beside my sister, facing the enemy: legal theory out of coalition. Stanford Law Review, 43(6), 1183-1192.

Meissner, F., \& Vertovec, S. (2015). Comparing super-diversity. Ethnic and Racial Studies, 38(4), 541-555.

Mittel, J. (2015). Complex TV: the poetics of contemporary television storytelling. New York: NYU Press.

Pisarevskaya, A., Levy, Scholten, P., \& Jansen, J. (2019). Mapping migration studies: an empirical analysis of the coming of age of a research field. Migration Studies https://doi.org/10.1093/migration/mnz031.

Portes, A., Guarnizo, L. E., \& Landolt, P. (1999). The study of transnationalism: Pitfalls and promises of an emergent research field. Ethnic and Racial Studies, 22(2), 217-237.

Scholten, P. W. A. (In press). Mainstreaming versus alienation: complexity and the dynamics of migration and diversity policy. Basingstoke: Palgrave.

Stark, O., \& Bloom, D. E. (1985). The new economics of labor migration. The American Economic Review, 75, 173-178.

Van Noorden, R. (2014). Global scientific output doubles every nine years. Nature Newsblog http://blogs.nature.com/news/2 014/05/global-scientific-output-doubles-every-nine-years.html.

Vertovec, S. (1999). Conceiving and researching transnationalism. Ethnic and Racial Studies, 22(2), 447-462.

Vertovec, S. (2007). Super-diversity and its implications. Ethnic and Racial Studies, 29(6), 1024-1054.

Vertovec, S. (2019). Talking around super-diversity. Ethnic and Racial Studies, 42, 125-139.

Wimmer, A., \& Glick Schiller, N. (2002). Methodological nationalism and beyond: Nation-state building, migration and the social sciences. Global Networks, 2(4), 301-334.

\section{Publisher's Note}

Springer Nature remains neutral with regard to jurisdictional claims in published maps and institutional affiliations. 